\title{
The First Isolable Low-valent Ferrocene Enabling the Application of Unprecedented Ferrocene Anolyte
}

Authors: Hayoung Song ${ }^{1 *}$, Giyun Kwon ${ }^{2}$, Cooper Citek $^{3}$, Seungwon Jeon ${ }^{1}$, Kisuk Kang, ${ }^{2,4,5 *}$ and Eunsung Lee ${ }^{1,6 \ddagger}$

\begin{abstract}
Affiliations:
${ }^{1}$ Department of Chemistry, Pohang University of Science and Technology. Pohang, 37673, Republic of Korea.

${ }^{2}$ Department of Materials Science and Engineering, Research Institute of Advanced Materials (RIAM), Seoul National University, 1 Gwanak Road, Seoul 151-742, Republic of Korea.

${ }^{3}$ Division of Chemistry and Chemical Engineering, California Institute of Technology (Caltech), Pasadena, California 91125, United States.

${ }^{4}$ Institute of Engineering Research, College of Engineering, Seoul National University, 1 Gwanak-ro, Gwanak-gu, Seoul 151-742, Republic of Korea.

${ }^{5}$ Center for Nanoparticle Research, Institute of Basic Science, Seoul National University, 1 Gwanak-ro, Gwanak-gu, Seoul 151-742, Republic of Korea.

${ }^{6}$ Division of Advanced Materials Science, Pohang University of Science and Technology. Pohang, 37673, Republic of Korea.

†Correspondence to: eslee@ postech.ac.kr (E.L.) and matlgen1@snu.ac.kr (K.K).

*Current Address: Center for Self-Assembly and Complexity (CSC), Institute for Basic Science (IBS), Pohang, 37673, Republic of Korea.
\end{abstract}

\begin{abstract}
Here, we report the first isolable low-valent biscyclopentadienyl iron complexes stabilized by NHC-functionalized ligands (NHC-Cps), which were characterized by electron paramagnetic resonance (EPR) and ${ }^{57} \mathrm{Fe}$ Mössbauer spectroscopy. Additional theoretical studies on these formally low-valent ferrocene complexes clearly explain the origin of their thermodynamic stability and the orbital interactions between iron and NHC-Cp. Exploiting the facile $\mathrm{Fe}(\mathrm{II} / \mathrm{I})$ redox chemistry, we successfully demonstrated that the NHC-Fc compounds can be applied as the first example of ferrocene anolyte for redox-flow batteries. These low-valent species will not only deepen our understanding of the intrinsic chemistry of low-valent ferrocene but have the potential to open the way for the rational design of low-valent metallocene derivatives for various applications.
\end{abstract}

\section{Main Text:}

Since its discovery by Pauson, Kealy, ${ }^{1}$ and Miller, ${ }^{2}$ the remarkable stability and reactivity of ferrocene have enabled its use in many applications, including electrochemistry, ${ }^{3}$ medicinal chemistry, ${ }^{4}$ bioorganometallic chemistry, ${ }^{5}$ host-guest chemistry, ${ }^{6}$ and transition metal catalysis. ${ }^{7}$ In particular, the pronounced reversible redox behavior of ferrocene solidifies its position in electrochemistry as a ubiquitous standard. Furthermore, the $\mathrm{Fe}(\mathrm{III}) / \mathrm{Fe}(\mathrm{IV})$ oxidation of ferrocenium has been achieved recently using a superacid medium. ${ }^{8}$ On the other hand, the synthesis of low-valent ferrocenes has not been successfully achieved and the only decomposition of the ferrocene unit in presence of strong reductants has been reported to date. ${ }^{9}$ Due to the high instability of low-valent ferrocenes, it was only possible to confirm a reversible 
reduction of ferrocene using cyclic voltammetry at low temperatures. ${ }^{10}$ The instability of the low-valent ferrocene is due to the facile dissociation of the cyclopentadienyl anion ligand (Cp), ${ }^{9}$ as indicated by trapping experiments. ${ }^{11}$ Despite numerous attempts to stabilize the lowvalent ferrocene by the introduction of functional groups on the cyclopentadienyl rings, a persistent low-valent ferrocene stable at room temperature could not be obtained ${ }^{12}$ (Figure 1a). Based on the fact that their high instability is caused by the dissociation of the cyclopentadienyl ligand, many attempts have been made to synthesize an isolobal structure of low-valent ferrocene stabilized by the introduction of other ligands. ${ }^{13,14}$ Astruc et al. reported the synthesis of an iron-based sandwich complex $\left[\mathrm{Fe}(\mathrm{Cp})\left(\eta^{6}-\mathrm{C}_{6} \mathrm{Me}_{6}\right)\right]^{14 \mathrm{a}}$ its derivatives. ${ }^{14 \mathrm{~b}}$ Tasumi et al. reported $\left[\left(\mathrm{Cp}^{*}\right) \mathrm{Fe}(\mu\right.$-polyarene $\left.) \mathrm{Fe}\left(\mathrm{Cp}^{*}\right)\right]$ complexes obtained by the reduction of halfsandwich $\mathrm{Fe}(\mathrm{II}) \mathrm{Cp} *$ compounds using potassium polyarenides.${ }^{14 \mathrm{c}}$ While previous studies on the reduction of heteroferrocenes to obtain low-valent heteroferrocenes had been unsuccessful, ${ }^{13 a-c}$ Saito et al. reported the synthesis of stable anionic stannaferrocene from the reaction between $\mathrm{Fe}(\mathrm{acac})_{3}$ and dilithiostannol. ${ }^{14 \mathrm{~d}}$ Recently, Mills and co-workers reported a fascinating work describing the characterization of ferrocenate under low temperature. ${ }^{15}$ Considering that the reduction of ferrocene occurs at high negative voltages $(-3.3 \mathrm{~V}$ vs $\left.\mathrm{Fc} / \mathrm{Fc}^{+}\right)^{15}$, it can be applied to a wide range of electrochemistry, including the design of anolyte for high energy battery. However, there is still no example of the synthesis and characterization of a stable low-valent ferrocene including two intact cyclopentadienyl ligands so far.

On the other hand, recently, interest in $N$-heterocyclic carbenes (NHCs) ${ }^{16}$ has increased due to their novel chemical properties, such as the reactivity towards small molecules. ${ }^{17}$ Especially, their amazing properties to stabilize electron-rich main-group elements, ${ }^{18}$ radicals, ${ }^{19}$ and transition-metal centers ${ }^{20}$ are enjoying the spotlight. However, the redox behavior of NHCs remains underexplored, presumably due to the thermodynamic instability of NHC radical ions generated by redox reactions. For example, the radical anion of triazol-5-ylidene was characterized by cyclic voltammetry and electron paramagnetic resonance (EPR) in $1997,{ }^{21}$ but there has been no report of an NHC radical cation produced by one-electron oxidation.

Nevertheless, the reactivity of NHCs with various oxidants has been studied. In 2004, the reactivity of imidazol-2-ylidene with tetracyanoethylene (TCNE) and a ferrocenium salt was reported by Clyburne et al. ${ }^{22}$ They showed that TCNE reacted with the NHC to produce a cationic dimer, formation of which was considered as evidence of an NHC radical cation intermediacy. However, direct observation of the NHC radical cation intermediate was not possible. Subsequently, a potential proton-catalyzed dimerization pathway was suggested as an alternative mechanism for the cationic dimer formation. ${ }^{23}$ This revised mechanism has been further strengthened by the inconsistency between the ionization energy of NHC $\left(7.68 \mathrm{eV}^{24}\right)$ and the electron affinity of TCNE $\left(3.16 \mathrm{eV}^{25}\right)$, as pointed out by the Arduengo group in $2015 .{ }^{26}$ Furthermore, Arduengo ${ }^{26}$ and our group ${ }^{27}$ have also reported various adducts obtained from the reaction between NHCs and TCNE.

Interestingly, Clyburne and coworkers showed that ferrocenium salts react with NHCs to produce imidazolium salts, not dicationic dimers. ${ }^{22}$ They have postulated that the unstable NHC radical cation intermediate likely abstracts a hydrogen atom from the THF solvent. As Arduengo argued, ${ }^{26}$ however, it is necessary to consider whether the charge transfer between an NHC and ferrocenium is thermodynamically feasible. In the light of their respective ionization potentials (NHC: $7.68 \mathrm{eV},{ }^{24}$ ferrocene: $6.81 \mathrm{eV}^{28}$ ), an alternative mechanism is needed to explain how the imidazolium salt forms. In addition, various phosphines, which are less nucleophilic than NHCs, were found to react with ferrocenium salts to produce ferrocenephosphine adducts. ${ }^{29}$ Inspired by this work, we speculated that ferrocene-NHC adducts could be formed by the direct reaction of NHCs with the $\mathrm{C}-\mathrm{H}$ bond of ferrocenium salts. Assuming 
we could access these ferrocene-NHC adducts, subsequent reduction yielding low-valent ferrocene complexes stabilized by the well-known $\pi$-accepting properties and significant steric hindrance of the NHC-derived fragment was considered feasible. Here, for the first time, we report the successful synthesis of $N$-heterocyclic carbene-functionalized cyclopentadiene iron complexes and elucidation of the first unambiguous one-electron reduction of ferrocene.

We first sought to investigate the imidazolium salts produced in the reaction of NHCs with ferrocenium salts, as reported by Clyburne. ${ }^{16}$ After the addition of 1,3-bis(2,6diisopropylphenyl)imidazol-2-ylidene (IPr) to ferrocenium hexafluorophosphate $\left(\mathrm{FcPF}_{6}\right)$ in THF at room temperature, the corresponding imidazolium salt and ferrocene were obtained. ${ }^{22}$ However, we were able to identify an additional component of the reaction mixture that has not been characterized previously. This product was identified as the NHC-functionalized ferrocenium (IPr-Fc adduct, 1a) and could be cleanly isolated in $56 \%$ yield. In the same manner, cyclic (alkyl)(amino)carbene (cAAC)-functionalized ferrocenium (cAAC-Fc adduct, 1b) was also successfully obtained in $46 \%$ isolated yield (Figure 1b).

a

Not persistent
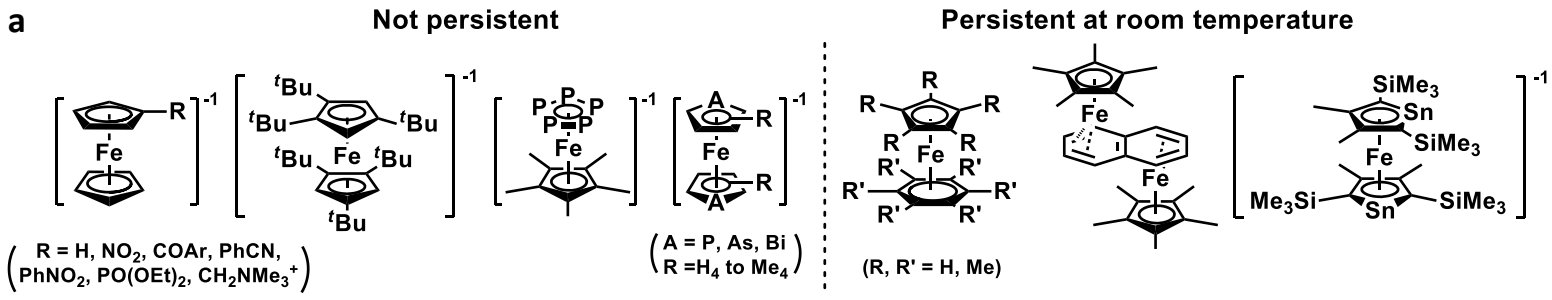

b
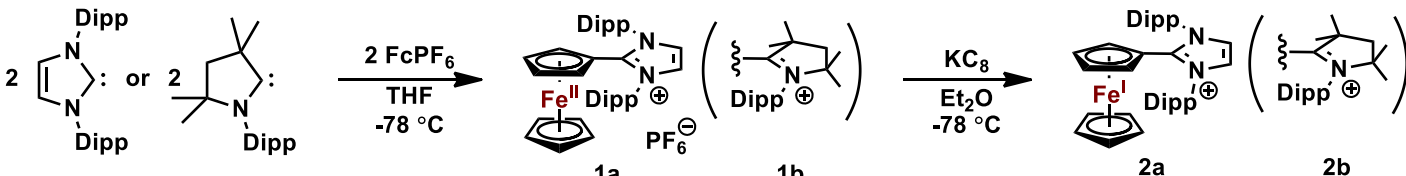

C
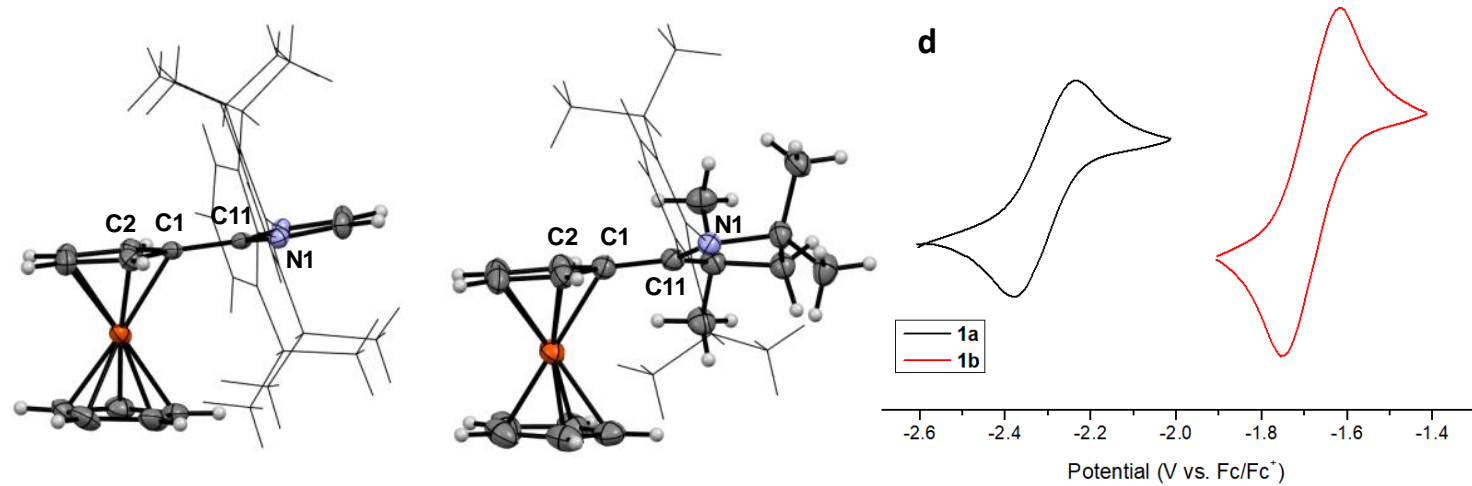

Figure 1. Synthesis of NHC-functionalized ferrocenes and their low-valent derivatives (a) Previous attempts to obtain persistent low-valent ferrocenes and their persistent isolobal structures. (b) Synthesis of $\mathbf{1 a}$ and $\mathbf{1 b}$ by the oxidative nucleophilic substitution of ferrocenium with NHCs and their further reduction to obtain $\mathbf{2 a}$ and $\mathbf{2} \mathbf{b}$, with formal oxidation states indicated. ( $\mathrm{Fc}=$ ferrocenium, Mes = 2,4,6-trimethylphenyl, Dipp = 2,6-diisopropylphenyl). (c) $\mathrm{X}$-ray crystallographic analysis of 1a and 1b. (d) Cyclic voltammograms of $\mathbf{1 a}$ and $\mathbf{1 b}$ in 0.1 $\mathrm{M}$ of $\left[\mathrm{Bu}_{4} \mathrm{~N}\right] \mathrm{PF}_{6} / \mathrm{MeCN}$ (vs. Fc/Fc ${ }^{+}$, scan rate $=0.1 \mathrm{~V} \mathrm{~s}^{-1}$ ).

Compared with the previous studies reported by Kunz ${ }^{30}$ and Yuan. ${ }^{31}$ NHC-functionalized ferrocene with high steric hindrance on imidazolium ring 1a is first reported. Furthermore, this is also the first report of cAAC-Fc adduct $\mathbf{1 b}$, which exhibits different chemical properties to 1a due to the greater $\pi$-accepting nature of cAAC compared to IPr. The stability of these NHC- 
Fc adducts may further enable research on ferrocene-based carbocation species, ${ }^{32}$ limited by dimerization pathways and dissociation of fulvene ligand from iron.

X-ray diffraction studies of $\mathbf{1 a}$ and $\mathbf{1 b}$ confirmed the NHC-Fc adduct structures (Figure 1c). The C1-C11 bond lengths of $1 \mathbf{a}(1.447(6) \AA)$ and $\mathbf{1 b}(1.446(2) \AA)$ are similar to Yuan's system $\left(1.437(9) \AA^{31 a}\right)$. 1a exhibits planarity across the cyclopentadiene and imidazolium rings $(\mathrm{C} 2-$ $\left.\mathrm{C} 1-\mathrm{C} 11-\mathrm{N} 1=0.81^{\circ}\right)$, in contrast to the distorted structures of $\mathbf{1 b}$ and Yuan's system $\left(17.22^{\circ}\right.$ and $38.83^{\circ 31 b}$ ) due to the 1,3-allylic strain between the NHC and Cp rings.

To understand the formation of the NHC-Fc adducts, we investigated three possible initial reaction pathways by density functional theory (DFT) calculations: ${ }^{29,33}$ (1) Oxidation of NHC by ferrocenium, (2) deprotonation of ferrocenium by NHC, and (3) nucleophilic addition of NHC to ferrocenium (Figure S2 and S3). The computational studies indicate that the nucleophilic addition of NHC to ferrocenium is the most favorable reaction pathway, consistent with the previously reported reaction between ferrocenium and phosphines. ${ }^{29}$ Due to the strong nucleophilicity of NHC, the activation barrier toward the nucleophilic addition of an NHC may be a much as $16 \mathrm{kcal} \mathrm{mol}^{-1}$ lower than the reaction with a phosphine. ${ }^{29}$

The UV-Vis spectra of $\mathbf{1 a}$ and $\mathbf{1 b}$ are shown in Figure S10. In the visible region, $\mathbf{1 a}$ and $\mathbf{1 b}$ show strong transitions at $471 \mathrm{~nm}\left(\varepsilon=2200 \mathrm{~cm}^{-1} \mathrm{M}^{-1}\right)$ and $551 \mathrm{~nm}\left(\varepsilon=5500 \mathrm{~cm}^{-1} \mathrm{M}^{-1}\right)$, respectively. Time-dependent DFT calculations of $\mathbf{1 a}$ and $\mathbf{1 b}$ at B3PW91/Def2-SVP level of theory predict a metal-to-ligand charge transfer (MLCT) in relatively good agreement with the experimental spectra (Figure S8 and S9). Interestingly, the differences in the transition energies were largely dependent on the LUMO orbitals, which are strongly influenced by the vacant porbital at the NHCs. Thus, the absorption band of $\mathbf{1 b}$ is red-shifted compared to that of $\mathbf{1 a}$, due to the stronger $\pi$-accepting nature of cAAC than IPr.

$1 \mathbf{a}$ and $\mathbf{1 b}$ exhibit irreversible oxidation near $0.60 \mathrm{~V}$ vs. $\mathrm{Fc} / \mathrm{Fc}^{+}$) (Figure S13). However, $\mathrm{Fe}(\mathrm{II}) / \mathrm{Fe}(\mathrm{I})$ reduction at $\mathrm{E}_{1 / 2}=-2.31 \mathrm{~V}(\mathbf{1 a})$ and $\mathrm{E}_{1 / 2}=-1.69 \mathrm{~V}(\mathbf{1 b})\left(\mathrm{vs} . \mathrm{Fc} / \mathrm{Fc}^{+}\right)$is reversible under inert conditions (Figure 1d). On the other hand, a reversible reduction of ferrocene is only observed at low temperature $\left(-50^{\circ} \mathrm{C}\right) .{ }^{10}$ The unusual reduction reversibility of these NHCFc species might be attributed to the radical stabilization effect of the NHC moiety ${ }^{19 a}, 19 \mathrm{~b}$ with the protection by sterically hindered substituents. To the best of our knowledge, intact lowvalent ferrocenes have never been reported due to their low chemical stability. ${ }^{9}$ Thus, we attempted to prepare the reduced NHC-Fc radicals $\mathbf{2} \mathbf{a}$ and $\mathbf{2} \mathbf{b}$ to confirm the stabilization effect of the NHC-Cp ligands on low-valent transition metal centers. Hence, reduction of 1a and $\mathbf{1 b}$ by $\mathrm{KC}_{8}$ in toluene at $-78{ }^{\circ} \mathrm{C}$ generates deep green and deep purple solutions of $\mathbf{2 a}$ and $\mathbf{2} \mathbf{b}$, respectively (Figure 1b). The UV-Vis spectra of $\mathbf{2 a}$ and $\mathbf{2 b}$ are shown in Figure S11. The nearinfrared (NIR) transition of 2a at $1036 \mathrm{~nm}$ is consistent with TD-DFT predictions (Figure S7). Interestingly, $\mathbf{2} \mathbf{a}$ and $\mathbf{2 b}$ immediately decomposed by attempted removal of the solvent under vacuum. Thus, $\mathbf{2} \mathbf{a}$ and $\mathbf{2} \mathbf{b}$ were isolated by the simple vaporization of solvent under ambient conditions in high yield (2a: $44 \%$ yield, $\mathbf{2 b}$ : $99 \%$ yield). The $\mathbf{2 a}$ and $\mathbf{2 b}$ are stable for several weeks at $-20{ }^{\circ} \mathrm{C}$ as solid and solution phase under an inert atmosphere.

2a and $\mathbf{2 b}$ show relatively high thermodynamic stability in toluene solution at room temperature, as monitored by UV-Vis-NIR spectroscopy (Figure S12). The remarkable stability of $\mathbf{2} \mathbf{a}$ and $\mathbf{2} \mathbf{b}$ contrasts with previous studies on the reduction of ferrocene and their derivatives. The previously reported ferrocene radical anion showed a short lifetime of minutes at low temperatures $\left(-50{ }^{\circ} \mathrm{C}\right)^{11 \mathrm{~b}}$ and the reduced radical structures of several ferrocene derivatives could only exist with a short lifetime from seconds to minutes at room temperature. ${ }^{12 b}$ On the other hand, $\mathbf{2 a}$ and $\mathbf{2 b}$ showed improved stability with a long lifetime in hours to days at room temperature (Figure S12). 


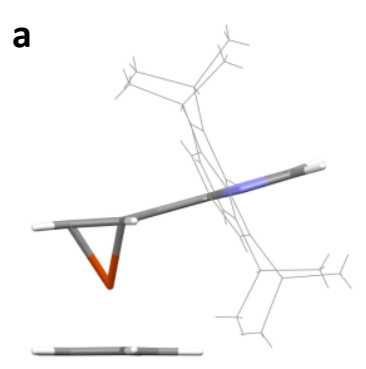

$2 a$

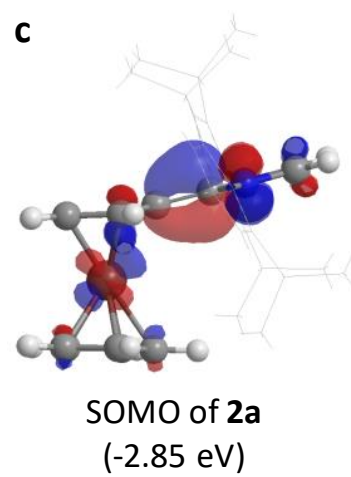

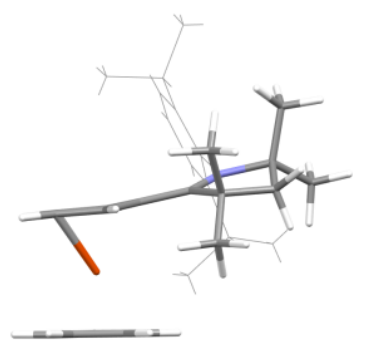

$2 b$

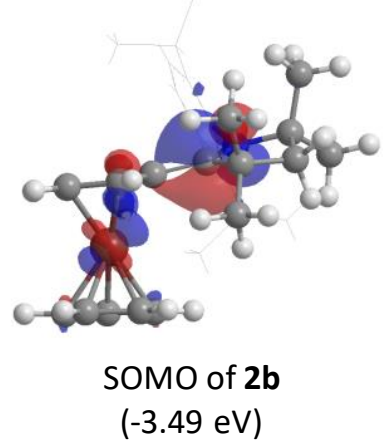

b

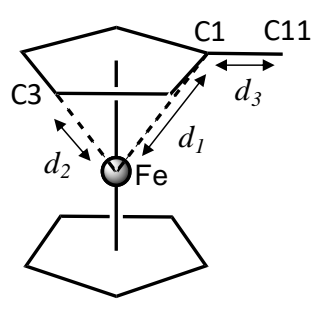

\begin{tabular}{cccc} 
& $d_{1}[\AA]$ & $d_{2}[\AA]$ & $d_{3}[\AA]$ \\
& \multicolumn{3}{c}{ (Wiberg Bond Order) } \\
$\mathbf{1 a}$ & 2.068 & 2.045 & 1.455 \\
& $(0.473)$ & $(0.510)$ & $(1.143)$ \\
& $\mathbf{2 . 2 4 3}$ & 2.020 & 1.406 \\
$\mathbf{2 a}$ & $\mathbf{( 0 . 2 7 3 )}$ & $(0.541)$ & $(1.328)$ \\
& 2.084 & 2.053 & 1.447 \\
$\mathbf{1 b}$ & $(0.474)$ & $(0.546)$ & $(1.208)$ \\
& $\mathbf{2 . 1 9 7}$ & 2.026 & 1.421 \\
$\mathbf{2 b}$ & $\mathbf{( 0 . 3 2 6 )}$ & $(0.538)$ & $(1.287)$
\end{tabular}

Figure 2. Structural characterization of low-valent ferrocenes with DFT-calculations (a) Optimized structures of $\mathbf{2 a}$ and $\mathbf{2 b}$ obtained using Gaussian 09W at B3PW91/Def2-SVP level. (b) SOMO of $\mathbf{2 a}$ and $\mathbf{2 b}$ (isovalue $=0.05$ (electrons $/$ bohr $\left.^{3}\right)^{1 / 2}$ ). (c) Selected bond lengths and Wiberg bond orders of $\mathbf{1} \mathbf{a}, \mathbf{2 a}, \mathbf{1 b}$, and $\mathbf{2 b}$. .

The structures of $\mathbf{2 a}$ and $\mathbf{2 b}$ are evaluated by DFT optimization (Figure 2a). Interestingly, $\mathbf{2 a}$ and $\mathbf{2 b}$ show a slight distortion of the NHC-substituted Cp ring (Figure 2b). The results might be explained by inspection of the half-filled SOMO orbitals of $\mathbf{2 a}$ and $\mathbf{2} \mathbf{b}$ showing anti-bonding character between $\mathrm{Fe}$ and $\mathrm{C} 1$ (Figure $\mathbf{2 c}$ ). The bond length between $\mathrm{Fe}-\mathrm{C} 1$ in $\mathbf{2 b}$ is shorter than that in 2a, presumably because the SOMO population in the $\pi$-orbital (between $\mathrm{C} 1-\mathrm{C} 11$ ) is more localized on C11 in $\mathbf{2 b}$ than it is in $\mathbf{2 a}$. We believe that the SOMO localization on the NHC moiety accounts for the bonding in $\mathbf{2 a}$ and $\mathbf{2} \mathbf{b}$ and explains the thermodynamic stability of the reduced species. Despite the increase in the length of Fe1-C1 and the decrease in the length of $\mathrm{C} 1-\mathrm{C} 11$ bond, the bond between $\mathrm{Fe} 1$ and $\mathrm{C} 1$ is still present and the $\mathrm{C} 1-\mathrm{C} 11$ bond remains in a single bond range. Thus, the NHC-Cp ligands of $\mathbf{2 a}$ and $\mathbf{2 b}$ still resemble the previously reported zwitterionic NHC-Cp structures ${ }^{30 a}$ but differ significantly from the structures of iron $\eta^{4}$-fulvene complexes ${ }^{34}$.

For a clear classification as fulvene, we also considered the bond-length alternation (BLA) parameter of several fulvene derivatives including 1a, 1b, 2a, and $\mathbf{2 b}$ (Figure S1). In the case of intact fulvenes $\mathbf{A}$ and $\mathbf{B}$, their BLA parameters are 11.9, which was close to polyethylene $(\sim 12)$. On the other hand, the BLA parameters of zwitterionic cyclopentadienide are low $(\mathbf{C}-$ 4.0 and D-2.1). Interestingly, the fulvene complex (E-H) showed a lower value (6.7-3.7) than intact fulvene (A, B), but still showed a higher value, which could be classified as a fulvene, than zwitterionic cyclopentadienide D. On the other hand, 1a, 1b, 2a, and $\mathbf{2 b}$ showed low values of BLA parameters $(0.9-2.7)$, which show a similar value with ferrocenyl carbocation (I, J). Thus, The ligands of $\mathbf{2 a}$ and $\mathbf{2 b}$, as well as $\mathbf{1 a}$ and $\mathbf{1 b}$, can be classified as cyclopentadienide.

Furthermore, the thermodynamic stability of $\mathbf{2 a}$ and $\mathbf{2 b}$ may in part be attributable to the spin delocalization from iron to the NHCs as calculated by DFT at the B3PW91/Def2-SVP level of 
theory. The Mulliken atomic spin densities of $\mathbf{2 a}$ and $\mathbf{2 b}$ localize on the iron atom at $50 \%$ and $28 \%$ and in the empty p-orbital of the NHCs at $29 \%$ and $58 \%$, respectively (Figure S5).
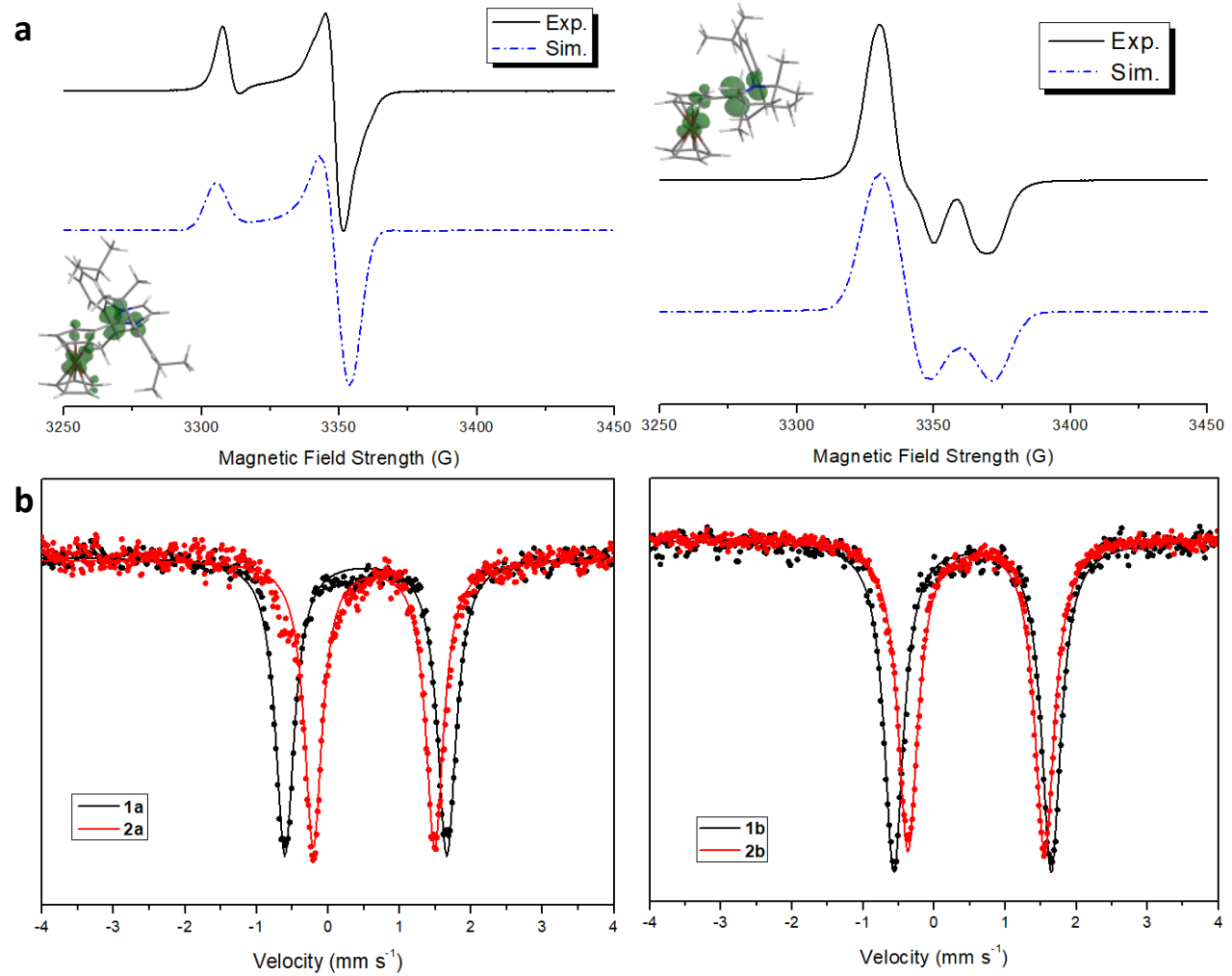

Figure 3. Spectroscopic characterization of low-valent ferrocene (a) X-band EPR spectrum of $\mathbf{2 a}$ and $\mathbf{2 b}$ in toluene at $160 \mathrm{~K}$ and the visualization of Mulliken spin densities of $\mathbf{2 a}$ and $\mathbf{2 b}$ $\left(\right.$ Gaussian 09W, B3PW91/Def2-SVP, isovalue $\left.=0.05\left(\text { electrons } / \text { bohr }^{3}\right)^{1 / 2}\right)$. (b) Frozen solution Mössbauer spectra of $\mathbf{1 a}, \mathbf{1 b}, \mathbf{2 a}$, and $\mathbf{2 b}$ collected at $80 \mathrm{~K}$ in the presence of a $50 \mathrm{mT}$ parallel magnetic field.

The X-band EPR spectroscopy data also confirm the low spin, iron-based ground states $(S=$ $1 / 2)$ of $\mathbf{2 a}(\mathrm{g}=[2.040,2.014,2.010])$ and $\mathbf{2 b}(\mathrm{g}=[2.027,2.019,2.000])$ (Figure 3a). The $\mathrm{g}$ values of $\mathbf{2 a}$ and $\mathbf{2 b}$ are similar to the g-value of the transient anionic ferrocene characterized previously by a continuous in-situ EPR electrochemical reactor. ${ }^{11 \mathrm{~b}}$ Additionally, the EPR spectra of $\mathbf{2 a}$ and $\mathbf{2 b}$ distinctly differ from the data obtained for "ferrocene-substituted radical anions," which exhibit narrow signals with well-resolved ${ }^{1} \mathrm{H}$ couplings and symmetry for the center of the spectra. ${ }^{12 b}$ The slightly rhombic spectra of $\mathbf{2 a}$ and $\mathbf{2} \mathbf{b}$ with comparatively wider, anisotropic signals are consistent with iron d-orbital character of the $S=1 / 2$ ground state. The aforementioned ferrocene-substituted radical anions are best described as ligand-based, organic radicals, in contrast to the partially iron-centered, metalloradicals $\mathbf{2 a}$ and $\mathbf{2 b}$.

We also performed ${ }^{57} \mathrm{Fe}$ Mössbauer spectroscopy of each compound in benzene or toluene solutions (Figure 3b). The ${ }^{57} \mathrm{Fe}$ Mössbauer spectra of $\mathbf{1 a}$ and $\mathbf{1 b}$ at $80 \mathrm{~K}$ feature symmetric quadrupole doublets at $\delta=0.53 \mathrm{~mm} \mathrm{~s}^{-1}$ (1a) and $0.54 \mathrm{~mm} \mathrm{~s}^{-1}$ (1) (compared to ferrocene at approximately $0.53 \mathrm{~mm} \mathrm{~s}^{-1}$ ) and quadrupole splitting $\Delta \mathrm{E}_{\mathrm{Q}}=2.27 \mathrm{~mm} \mathrm{~s}^{-1}$ (1a) and $2.22 \mathrm{~mm} \mathrm{~s}^{-1}$ (1b) (cf. $2.40 \mathrm{~mm} \mathrm{~s}^{-1}$ for ferrocene). ${ }^{35}$ However, the spectra of their reduced forms $\mathbf{2 a}$ and $\mathbf{2 b}$ are in both cases positively shifted to $\delta=0.64 \mathrm{~mm} \mathrm{~s}^{-1}(\mathbf{2 a})$ and $0.59 \mathrm{~mm} \mathrm{~s}^{-1}(\mathbf{2 b})$ and narrowed to $\Delta \mathrm{E}_{\mathrm{Q}}=1.70 \mathrm{~mm} \mathrm{~s}^{-1}(\mathbf{2 a})$ and $1.92 \mathrm{~mm} \mathrm{~s}^{-1}(\mathbf{2 b})$. The Mössbauer parameters for all four compounds are well-reproduced by a calibrated DFT method (see Supplementary Materials), and single-point calculations recapitulate the shared electron density between iron and the NHC. 
To the best of our knowledge, there is no reported measurement of the Mössbauer parameters for a reduced, formally Fe(I) biscyclopentadienyl anion. Instead, the Mössbauer parameters of 2a and $\mathbf{2 b}$ can be indirectly validated by comparison with the similar quadrupole doublets of isolobal bis-Fe(I) sandwich complexes reported by Astruc et al. $\left(\delta=0.56-0.66 \mathrm{~mm} \mathrm{~s}^{-1}\right.$ and $\Delta \mathrm{E}_{\mathrm{Q}}$ $=1.31-1.66 \mathrm{~mm} \mathrm{~s}^{-1}$ between 10 and $\left.260 \mathrm{~K}\right)^{14 \mathrm{~b}}$ and Tasumi et al. $\left(\delta=0.59 \mathrm{~mm} \mathrm{~s}^{-1}\right.$ and $\Delta \mathrm{E}_{\mathrm{Q}}=$ $1.55-1.59 \mathrm{~mm} \mathrm{~s}^{-1}$ at $\left.90 \mathrm{~K}\right) .{ }^{14 \mathrm{c}}$ On the other hand, $\mathrm{Fe}(\mathrm{I})-\mathrm{CpFe}\left(\mathrm{C}_{6} \mathrm{H}_{6}\right)$ exhibits a quadrupole doublet near $\delta=0.92-0.87 \mathrm{~mm} \mathrm{~s}^{-1}\left(\Delta \mathrm{E}_{\mathrm{Q}}=1.20-0.95 \mathrm{~mm} \mathrm{~s}^{-1}\right.$ between 4.2 and $\left.260 \mathrm{~K}\right)$, potentially excluding decomposition of the reduced products $\mathbf{2 a}$ and $\mathbf{2 b}$ to similar solvent adducts. ${ }^{14 a}$ An increase in the measured isomer shift would be expected with a slight elongation of the $\mathrm{Fe}-\mathrm{C}$ bonds in the complexes upon reduction; the narrowing of the quadrupole splitting is consistent with increased electron density in axial $d_{x z} / d_{y z}$-based SOMO orbitals orthogonal to the equatorial $\mathrm{d}_{\mathrm{xy}} / \mathrm{d}_{\mathrm{x} 2-\mathrm{y} 2} \mathrm{HOMO}$ orbitals of $\mathrm{Fe}(\mathrm{II})$ in $\mathbf{1 a}$ and $\mathbf{1 b} .{ }^{36}$ This investigation of the electronic environment of low-valent ferrocenes $\mathbf{2 a}$ and $\mathbf{2} \mathbf{b}$ supports the iron-based spin and lower valence state of $\mathbf{2} \mathbf{a}$ and $\mathbf{2 b}$ with respect to $\mathbf{1 a}$ and $\mathbf{1 b}$.
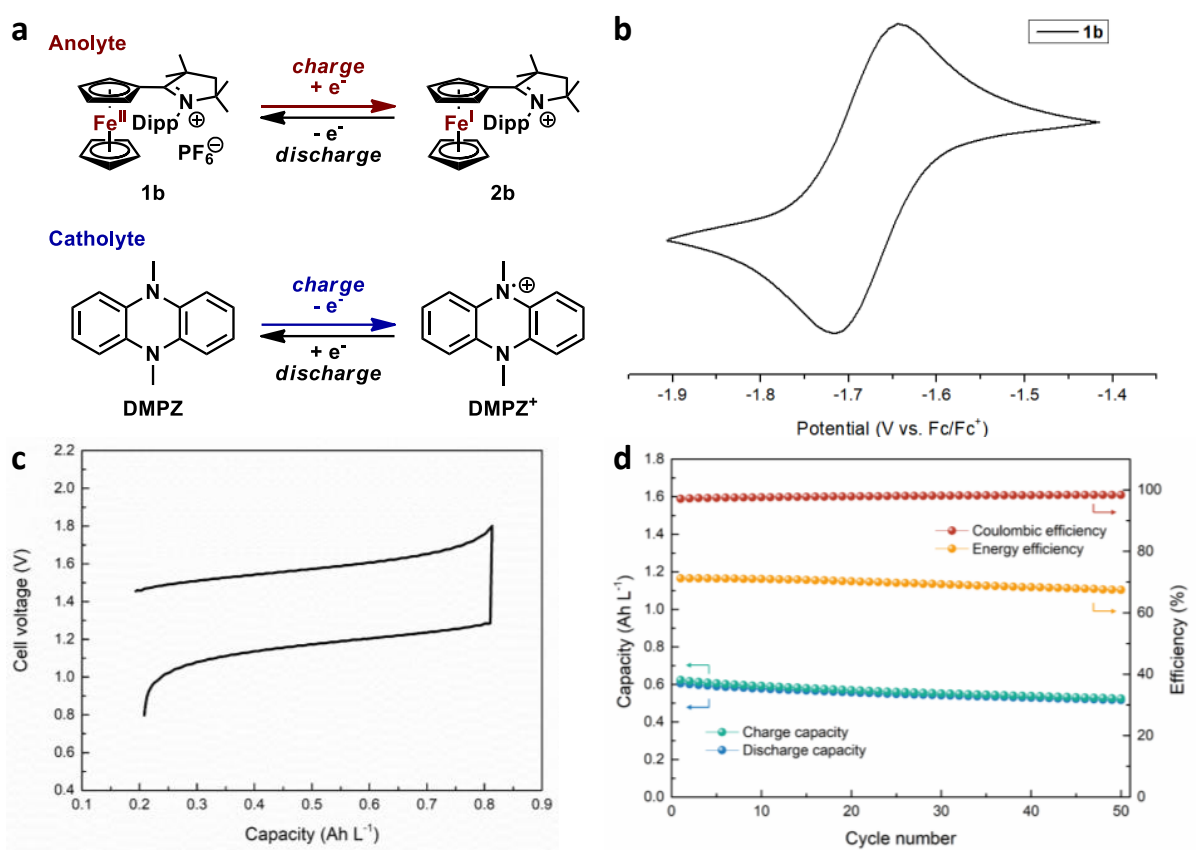

Figure 4. Application of low-valent ferrocenes in redox-flow battery (a) Redox mechanism of $\mathbf{1 b}$ and DMPZ in a flow cell. (b) Cyclic voltammogram of $\mathbf{1 b}$ in $0.5 \mathrm{M} \mathrm{LiTFSI} / \mathrm{MeCN}$ (vs. $\mathrm{Fc} / \mathrm{Fc}^{+}$, scan rate $=0.1 \mathrm{~V} \mathrm{~s}^{-1}$ ). (c) Cell voltage vs. cell capacity. (d) Cycling efficiencies and capacities with 50 cycles.

Most applications of ferrocene derivatives have been limited to their oxidation chemistry due to their redox instability at negative potentials. ${ }^{37}$ However, we found that $\mathbf{1 b}$, which exhibits a reversible $\mathrm{Fe}(\mathrm{II}) / \mathrm{Fe}$ (I) redox cycle, could be studied in a redox-flow battery (RFB) system as the first example of ferrocene anolyte. ${ }^{38}$ Considering its remarkable stability, moderate reduction potential $\left(-1.69 \mathrm{~V}\right.$ vs $\mathrm{Fc} / \mathrm{Fc}^{+}$in $\left.0.1 \mathrm{M}\left[\mathrm{Bu}_{4} \mathrm{~N}\right] \mathrm{PF}_{6} / \mathrm{MeCN}\right)$, and high solubility $(0.561$ $\mathrm{M})$ in $\mathrm{MeCN}$, we believed that $\mathbf{1 b}$ could serve as a good anolyte candidate in a highperformance RFB. To construct an all-organic RFB, ${ }^{39}$ commercially available 5,10dimethyldihydrophenazine (DMPZ) was employed as a counter catholyte material (Figure 4a); DMPZ undergoes a reversible redox reaction at $-0.26 \mathrm{~V}$ vs. $\mathrm{Fc} / \mathrm{Fc}^{+} .{ }^{40} \mathrm{As}$ shown in Figure $4 \mathbf{b}$, $\mathbf{1 b}$ in $\mathrm{MeCN}$ with $0.5 \mathrm{M}$ LiTFSI supporting electrolyte shows a reversible single-electron redox event at $-1.68 \mathrm{~V} \mathrm{vs}$. $\mathrm{Fc} / \mathrm{Fc}^{+}$, yielding a theoretical cell voltage of $1.42 \mathrm{~V}$ in a flow battery when coupled with DMPZ. 
The electrochemical performance of the flow cell employing the DMPZ/1b system was also investigated using a customized flow cell (see Supplementary Materials). Figure 4c shows a representative charge-discharge curve at a current density of $20 \mathrm{~mA} \mathrm{~cm}{ }^{-2}$. An average cell voltage of $1.40 \mathrm{~V}$ was achieved, consistent with the cyclic voltammetry data. It should be noted that the initial capacity of $0.62 \mathrm{Ah} \mathrm{L}^{-1}$ is reasonably close to the theoretical capacity of 0.80 $\mathrm{Ah} \mathrm{L}^{-1}$, indicating material utilization of $\sim 78 \%$. The cycling efficiency and capacity retention data for the RFB indicate that the flow cell maintains a high coulombic efficiency (CE) of $\sim 99 \%$, a voltage efficiency of $\sim 71 \%$, and acceptable energy efficiency (EE) of $\sim 70 \%$ over 50 cycles (Figure 4d). Additionally, stable cycling is maintained in the flow cell without noticeable capacity degradation over 50 cycles, which is mainly attributed to the high stability of $\mathbf{2 b}$ in the solution phase. These results illustrate that electrochemistry based on low-valent $\mathrm{Fe}(\mathrm{I}) / \mathrm{Fe}$ (II) ferrocene redox couples is feasible in practical battery operation and is enabled by the stereoelectronic stabilization of low-valent ferrocene by NHC moieties.

Ferrocene, one of the most representative compounds in the discipline of organometallic chemistry, attracted much attention because of its extremely high thermal, chemical, and $\mathrm{Fe}(\mathrm{II} / \mathrm{III})$ redox stability. However, a well-characterized reduced ferrocene has not been achieved to date due to the fast dissociation of the cyclopentadienyl anion ligands from $\mathrm{Fe}(\mathrm{I})$. Thus, an $\mathrm{Fe}(\mathrm{I})$ biscyclopentadiene complex remained elusive for a long time. Here, we have shown that low-valent ferrocene derivatives $\mathbf{2 a}$ and $\mathbf{2 b}$ can be prepared by the one-electron reduction of $\mathbf{1 a}$ and $\mathbf{1 b}$ at ambient conditions, as confirmed by several complementary spectroscopic and theoretical methods. Additionally, a potential application in a redox-flow battery was successfully demonstrated using $\mathbf{1 b}$ as the first example of ferrocene anolyte, in part due to the high degree of stabilization of low-valent state by the cAAC moiety. These NHC-Fc complexes may deepen our understanding of the electrochemical behavior of ferrocene compounds and open the way to the rational design of low-valent ferrocene derivatives.

Acknowledgments: The X-ray crystallography analysis with synchrotron radiation was performed at the Pohang Accelerator Laboratory (PLS-II BL2D SMC beamline). This work was supported by a National Research Foundation of Korea (NRF) grant funded by the Korean government [Ministry of Science, ICT and Future Planning (MSIP)] (No. NRF2016H1A2A1907122 - Global Ph.D. Fellowship Program, NRF-2018R1A4A1024713, and NRF-2019M1A2A2067940). We thank Prof. Jonas C. Peters for use of the Mössbauer spectroscopy and Dr. Ewa Pietrasiak for helpful discussions. Author contributions: E.L. and H.S. conceived and designed the project. H.S. performed the synthesis and full characterizations of each compound, performed the computational studies and wrote the manuscript. K.K oversaw the redox-flow battery investigation, and G.K. performed the experiments. C.C. performed ${ }^{57} \mathrm{Fe}$ Mössbauer spectroscopy measurements and DFT Mössbauer predictions. S.J. assisted in the synthesis of 1a and 2a. E.L. managed and guided the project and revised the manuscript. All authors discussed the results and commented on the manuscript.; Competing interests: Authors declare no competing interests. Data and materials availability: The crystallographic data for $\mathbf{1 a}$ and $\mathbf{1 b}$ are deposited in the Cambridge Crystallographic Data Centre (CCDC) with deposition numbers CCDC 1940623 and 1940622.

\section{Supplementary Materials:}

Materials and Methods 
Figures S1-S21

Tables S1-S3

\section{References and Notes:}

(1) Kealy, T. J.; Pauson, P. L., A New Type of Organo-Iron Compound. Nature 1951, 168, 1039.

(2) Miller, S. A.; Tebboth, J. A.; Tremaine, J. F., 114. Dicyclopentadienyliron. J. Chem. Soc. 1952, 632 .

(3) Gagne, R. R.; Koval, C. A.; Lisensky, G. C., Ferrocene as an Internal Standard for Electrochemical Measurements. Inorg. Chem. 1980, 19, 2854.

(4) Patra, M.; Gasser, G., The Medicinal Chemistry of Ferrocene and Its Derivatives. Nat. Rev. Chem. 2017, 1, 0066.

(5) van Staveren, D. R.; Metzler-Nolte, N., Bioorganometallic Chemistry of Ferrocene. Chem. Rev. 2004, 104, 5931.

(6) Ko, Y. H.; Hwang, I.; Lee, D.-W.; Kim, K., Ultrastable Host-Guest Complexes and Their Applications. Isr. J. Chem. 2011, 51, 506.

(7) Gómez Arrayás, R.; Adrio, J.; Carretero, J. C., Recent Applications of Chiral Ferrocene Ligands in Asymmetric Catalysis. Angew. Chem. Int. Ed. 2006, 45, 7674.

(8) Malischewski, M.; Adelhardt, M.; Sutter, J.; Meyer, K.; Seppelt, K., Isolation and Structural and Electronic Characterization of Salts of the Decamethylferrocene Dication. Science 2016, 353,678 .

(9) Trifan, D. S.; Nicholas, L., Reductive Cleavage of Ferrocene. J. Am. Chem. Soc. 1957, 79, 2746.

(10) Ito, N.; Saji, T.; Aoyagui, S., Electrochemical Formation of Stable Ferrocene Anion and the Formal Rate Constant of the Ferrocene ${ }^{0 /-}$ Electrode. J. Organomet. Chem. 1983, 247, 301. (11) (a) Brown, A. D.; Reich, H., Reductive Cleavage of Ferrocene Derivatives. J. Org. Chem. 1970, 35, 1191; (b) Khrizanforov, M.; Strekalova, S.; Kholin, K.; Khrizanforova, V.; Grinenko, V.; Gryaznova, T.; Budnikova, Y., One-Stage Synthesis of $\mathrm{FcP}(\mathrm{O})\left(\mathrm{OC}_{2} \mathrm{H}_{5}\right)_{2}$ from Ferrocene and $\alpha$-Hydroxyethylphosphonate. $R S C A d v$. 2016, 6, 42701.

(12) (a) Slocum, D. W.; Jones, W. E.; Crimmins, T. F.; Hauser, C. R., Reduction of Ferrocene Methiodides. Synthesis of the Dimethylferrocenes. J. Org. Chem. 1969, 34, 1973; (b) Elschenbroich, C.; Cais, M., Organometallic Studies XXIX. Electron Spin Resonance of Ferrocene-Substituted Radical Anions. J. Organomet. Chem. 1969, 18, 135.

(13) (a) Lemoine, P.; Gross, M.; Braunstein, P.; Mathey, F.; Deschamps, B.; Nelson, J. H., Electrochemistry of Phosphaferrocenes. 1. Comparison of the Redox Properties of Ferrocene, Diphosphaferrocene, 3,4-Dimethyl-1-Phosphaferrocene and 3,3',4,4'-Tetramethyl-1,1'Diphosphaferrocene. Organometallics 1984, 3, 1303; (b) Ashe, A. J.; Al-Ahmad, S.; Pilotek, S.; Puranik, D. B.; Elschenbroich, C.; Behrendt, A., Comparison of the Properties of Polymethyl-1,1'-Diheteroferrocenes of the Group 15 Elements. Organometallics 1995, 14, 2689; (c) Winter, R. F.; Geiger, W. E., Electron-Transfer Properties of Cp*FeP 5 : Evidence for Dimerization Reactions Following Both Oxidation and Reduction. Organometallics 1999, 18, 1827; (d) Greer, S. M.; Üngor, Ö.; Beattie, R. J.; Kiplinger, J. L.; Scott, B. L.; Stein, B. W.; Goodwin, C. A. P., Low-Spin 1,1'-Diphosphametallocenates of Chromium and Iron. Chem. Commun. 2021, DOI: 10.1039/D0CC06518H.

(14) (a) Hamon, J. R.; Astruc, D.; Michaud, P., Syntheses, Characterizations, and Stereoelectronic Stabilization of Organometallic Electron Reservoirs: The 19-Electron $\mathrm{d}^{7}$ Redox Catalysts . $\eta^{5}-\mathrm{C}_{5} \mathrm{R}_{5} \mathrm{Fe}-\eta^{6}-\mathrm{C}_{6} \mathrm{R}_{6}^{\prime}$. J. Am. Chem. Soc. 1981, 103, 758; (b) Rabaa, H.; Lacoste, M.; Delville-Desboise, M.-H.; Ruiz, J.; Gloaguen, B.; Ardoin, N.; Astruc, D.; Beuze, 
A. L.; Saillard, J.-Y., Electronic Interplay between Two Iron Centers across Polyaromatic Ligands: Syntheses, Redox Chemistry, and Electronic Structures of the Electron-Reservoir 36to 38-Electron Complexes $\left[(\mathrm{FeCp})_{2}\left(\mu_{2}-\eta^{12} \text {-Polyaromatic }\right)\right]^{\mathrm{q}^{+}}(\mathrm{q}=0-2)$ Including Mixed Valences and Biradicals. Organometallics 1995, 14, 5078; (c) Hatanaka, T.; Ohki, Y.; Kamachi, T.; Nakayama, T.; Yoshizawa, K.; Katada, M.; Tatsumi, K., Naphthalene and Anthracene Complexes Sandwiched by Two $\left\{\left(\mathrm{Cp}^{*}\right) \mathrm{Fe}^{\mathrm{I}}\right\}$ Fragments: Strong Electronic Coupling between the $\mathrm{Fe}^{\mathrm{I}}$ Centers. Chem. Asian. J. 2012, 7, 1231; (d) Saito, M.; Matsunaga, N.; Hamada, J.; Furukawa, S.; Tada, T.; Herber, R. H., Anionic Stannaferrocene and Its Unique Electronic State. Chem. Lett. 2019, 48, 163.

(15) Goodwin, C. A. P.; Giansiracusa, M. J.; Greer, S. M.; Nicholas, H. M.; Evans, P.; Vonci, M.; Hill, S.; Chilton, N. F.; Mills, D. P., Isolation and Electronic Structures of Derivatized Manganocene, Ferrocene and Cobaltocene Anions. Nat. Chem. 2020, DOI: 10.1038/s41557020-00595-w.

(16) Hopkinson, M. N.; Richter, C.; Schedler, M.; Glorius, F., An Overview of N-Heterocyclic Carbenes. Nature 2014, 510, 485.

(17) (a) Martin, D.; Soleilhavoup, M.; Bertrand, G., Stable Singlet Carbenes as Mimics for Transition Metal Centers. Chem. Sci. 2011, 2, 389; (b) Song, H.; Kim, Y.; Park, J.; Kim, K.; Lee, E., Activation of Small Molecules at N-Heterocyclic Carbene Centers. Synlett 2016, 27, 477.

(18) Nesterov, V.; Reiter, D.; Bag, P.; Frisch, P.; Holzner, R.; Porzelt, A.; Inoue, S., NHCs in Main Group Chemistry. Chem. Rev. 2018, 118, 9678.

(19) (a) Martin, C. D.; Soleilhavoup, M.; Bertrand, G., Carbene-Stabilized Main Group Radicals and Radical Ions. Chem. Sci. 2013, 4, 3020; (b) Kim, Y.; Lee, E., Stable Organic Radicals Derived from N-Heterocyclic Carbenes. Chem. Eur. J. 2018, 24, 19110; (c) Kundu, S.; Sinhababu, S.; Chandrasekhar, V.; Roesky, H. W., Stable Cyclic (Alkyl)(Amino)Carbene (cAAC) Radicals with Main Group Substituents. Chem. Sci. 2019, 10, 4727.

(20) Roy, S.; Mondal, K. C.; Roesky, H. W., Cyclic Alkyl(Amino) Carbene Stabilized Complexes with Low Coordinate Metals of Enduring Nature. Acc. Chem. Res. 2016, 49, 357.

(21) Enders, D.; Breuer, K.; Raabe, G.; Simonet, J.; Ghanimi, A.; Stegmann, H. B.; Teles, J. H., A Stable Carbene as $\pi$-Acceptor Electrochemical Reduction to the Radical Anion. Tetrahedron Lett. 1997, 38, 2833.

(22) Ramnial, T.; McKenzie, I.; Gorodetsky, B.; Tsang, E. M. W.; Clyburne, J. A. C., Reactions of N-Heterocyclic Carbenes (NHCs) with One-Electron Oxidants: Possible Formation of a Carbene Cation Radical. Chem. Commun. 2004, 1054.

(23) Canal, J. P.; Ramnial, T.; Dickie, D. A.; Clyburne, J. A. C., From the Reactivity of NHeterocyclic Carbenes to New Chemistry in Ionic Liquids. Chem. Commun. 2006, 1809.

(24) Arduengo, A. J.; Bock, H.; Chen, H.; Denk, M.; Dixon, D. A.; Green, J. C.; Herrmann, W. A.; Jones, N. L.; Wagner, M.; West, R., Photoelectron Spectroscopy of a Carbene/Silylene/Germylene Series. J. Am. Chem. Soc. 1994, 116, 6641.

(25) Khuseynov, D.; Fontana, M. T.; Sanov, A., Photoelectron Spectroscopy and Photochemistry of Tetracyanoethylene Radical Anion in the Gas Phase. Chem. Phys. Lett. 2012, $550,15$.

(26) Arduengo III, A. J.; Calabrese, J. C.; Marshall, W. J.; Runyon, J. W.; Schiel, C.; Schinnen, C.; Tamm, M.; Uchiyama, Y., Imidazol-2-Ylidene Reactivity Towards Cyanocarbons. Z. Anorg. Allg. Chem 2015, 641, 2190.

(27) Song, H.; Kim, Y.; Park, J.; Ko, Y. H.; Kim, K.; Lee, E., An N-Heterocyclic-CarbeneTetracyanoethylene Zwitterion: Experimental and Theoretical Study on Its Formation and Reactivity. Eur. J. Org. Chem. 2017, 1231.

(28) Meot-Ner, M., Ion Chemistry of Ferrocene. Thermochemistry of Ionization and 
Protonation and Solvent Clustering. Slow and Entropy-Driven Proton-Transfer Kinetics. J. Am. Chem. Soc. 1989, 111, 2830.

(29) Chamkin, A. A.; Krivykh, V. V.; Nikitin, O. M.; Kreindlin, A. Z.; Shteltser, N. A.; Dolgushin, F. M.; Artyushin, O. I.; Ikonnikov, N. S.; Borisov, Y. A.; Belousov, Y. A., et al., Direct Phosphination of Ferrocenium Ion with Tertiary Phosphines by the Mechanism of Oxidative Nucleophilic Substitution. Eur. J. Inorg. Chem. 2018, 4494.

(30) (a) Kunz, D.; Johnsen, E. Ø.; Monsler, B.; Rominger, F., Highly Ylidic Imidazoline-Based Fulvenes as Suitable Precursors for the Synthesis of Imidazolium-Substituted Metallocenes. Chem. Eur. J. 2008, 14, 10909; (b) Schmid, D.; Seyboldt, A.; Kunz, D., A Direct Synthesis of a Strongly Zwitterionic 6,6'-Diaminofulvalene. Z. Naturforsch. B Chem. Sci. 2014, 69, 580.

(31) (a) Wang, J.; Feng, L.; Ma, F.; Lin, F.; Xie, L.; Yuan, Y., Synthesis, Crystal Structure and Properties of Iodide and Hexafluorophosphate Salts of 2-Ferrocenyl (or Binuclear Ferrocenyl)1,3-Dialkylbenzimidazolium. Chin. J. Org. Chem. 2012, 32, 1479 ; (b) Lai, Z.-M.; Ye, H.-M.; Wan, Q.; Xie, L.-L.; Bai, S.; Yuan, Y.-F., Synthesis, Crystal Structure and Properties of Benzimidazole-Bridged Dinuclear Ferrocenyl Derivatives. J. Mol. Struct. 2014, 1059, 33.

(32) Gleiter, R.; Bleiholder, C.; Rominger, F., A-Metallocenylmethylium Ions and Isoelectronic Fulvene Complexes of $\mathrm{d}^{6}$ to $\mathrm{d}^{9}$ Metals. Structural Considerations. Organometallics 2007, 26, 4850 .

(33) Babin, V. N.; Belousov, Y. A.; Belousova, T. A.; Borisov, Y. A.; Gumenyuk, V. V.; Nekrasov, Y. S., Reactions of Ferricinium Salts with Lewis Bases. Russ. Chem. Bull. 2011, 60, 2081.

(34) Edelmann, F.; Lubke, B.; Behrens, U., Pbergangsmetall-Fulven-Komplexe, XVIII. Pber (Fulven)Nickel(0)-Komplexe. Strukturvergleich Von (1,5-Cyclooctadien)(6,6Diphenylfulven)Nickel Und Tricarbonyl-(6,6-Diphenylfulven)Eisen. Chem. Ber. 1982, 115, 1325.

(35) Good, M. L.; Buttone and, J.; Foyt, D., MoSsbauer Spectroscopy of Metal Sandwich Compounds. Ann. N. Y. Acad. Sci. 1974, 239, 193.

(36) Guitlich, P.; Bill, E.; Trautwein, A., Mö̈sbauer Spectroscopy and Transition Metal Chemistry: Fundamentals and Application. Springer: Berlin, Heidelberg, 2011.

(37) Astruc, D., Why Is Ferrocene So Exceptional? Eur. J. Inorg. Chem. 2017, 2017, 6.

(38) Soloveichik, G. L., Flow Batteries: Current Status and Trends. Chem. Rev. 2015, 115, 11533.

(39) Leung, P.; Shah, A. A.; Sanz, L.; Flox, C.; Morante, J. R.; Xu, Q.; Mohamed, M. R.; Ponce de León, C.; Walsh, F. C., Recent Developments in Organic Redox Flow Batteries: A Critical Review. J. Power Sources 2017, 360, 243.

(40) (a) Kwon, G.; Lee, S.; Hwang, J.; Shim, H.-S.; Lee, B.; Lee, M. H.; Ko, Y.; Jung, S.-K.; $\mathrm{Ku}, \mathrm{K}$.; Hong, J., et al., Multi-Redox Molecule for High-Energy Redox Flow Batteries. Joule 2018, 2, 1771; (b) Kwon, G.; Lee, K.; Lee, M. H.; Lee, B.; Lee, S.; Jung, S.-K.; Ku, K.; Kim, J.; Park, S. Y.; Kwon, J. E., et al., Bio-Inspired Molecular Redesign of a Multi-Redox Catholyte for High-Energy Non-Aqueous Organic Redox Flow Batteries. Chem 2019, 5, 2642; (c) Lee, M.; Hong, J.; Lee, B.; Ku, K.; Lee, S.; Park, C. B.; Kang, K., Multi-Electron Redox Phenazine for Ready-to-Charge Organic Batteries. Green Chem. 2017, 19, 2980. 